\title{
Utilization of a Computer-Assisted Sperm Motion Analysis System to Examine Effects of Dinoseb on Rat Sperm
}

\author{
Masako SATO ${ }^{1)}$, Ryo OHTA ${ }^{1)}$, Kazuyoshi WADA ${ }^{1)}$, \\ Hideki MARUMO' ${ }^{1)}$, Mariko SHIROTA ${ }^{1)}$ and Tetsuji NAGAO ${ }^{2)}$ \\ ${ }^{1)}$ Safety Testing Laboratory, ${ }^{2)}$ Laboratory of Reproductive and Developmental Toxicology, \\ Food and Drug Safety Center, Hatano Research Institute, 729-5 Ochiai, Hadano, \\ Kanagawa 257-8523, Japan
}

\begin{abstract}
The computer-assisted sperm motion analysis (CASA) system has been used as one of the useful means for reproductive toxicity studies in male animals. Since various parameters of sperm motility are measured by the CASA system, we investigated the effects of a herbicide dinoseb, a testicular toxicant, and which parameter was the most appropriate for detecting changes. Crj:CD(SD)IGS mature male rats were administered dinoseb at a dose of 0 (corn oil), 5 or $7.5 \mathrm{mg} / \mathrm{kg}$ for 3 consecutive days, and were necropsied for cauda epididymal sperm analysis after a 12-day (Day15) or 19-day (Day 22) withdrawal period (Experiment I). No sperm motility parameters of dinoseb-treated rats were changed on Day 15, but on Day 22, the percentage of motile sperm (MOT) was significantly decreased in rats treated with dinoseb at $7.5 \mathrm{mg} / \mathrm{kg}$. Other parameters, such as path velocity (VAP), curvilinear velocity (VCL), and amplitude of lateral head displacement (ALH) were significantly decreased as well. In Experiment II, no parameters of sperm motility showed any change in rats treated with dinoseb at $7.5 \mathrm{mg} / \mathrm{kg}$ three times per week when evaluated on Day 21. It was concluded that MOT, VAP, VCL, and ALH were more sensitive to dinoseb effects on sperm in the CASA system.
\end{abstract}

Key words: CASA system, Dinoseb, Sperm motility, Sperm counts, Rat.

(J. Reprod. Dev. 46: 279-286, 2000)

$\mathbf{R}$ ecently, in reproductive toxicity studies, it is recommended to examine sperm parameters such as motility, morphology and counts, because the mating experiment alone is not sensitive enough as an endpoint to evaluate male fertility in rodents [1-5]. The computer-assisted sperm motion analysis (CASA) system has been utilized as one of the useful analytical methods in reproductive toxicity studies to evaluate the functional integrity of the testis or epididymis in rodents [6-8]. Although not only the percentage of motile sperm, but also various parameters for the

Accepted for publication: May 29, 2000

Correspondence: M. Sato sperm motion are obtained by the CASA system, it is still unanswered which parameter is the most sensitive measure and appropriate for detecting the toxic effects of compounds. Furthermore, when the toxic effects on the sperm quality are examined, the duration of spermatogenesis and sperm maturation must also be considered [9]. Therefore, flexible and optimal study designs for each compound are required to evaluate the toxicity in the case of short duration studies.

Dinoseb (2-sec-butyl 4,6-dinitrophenol) was widely used as a herbicide or insecticide. Dinoseb can act as an uncoupler of the mitochondrial oxidative phosphorylation, has high acute oral toxicity $\left(\mathrm{LD}_{50}\right.$ in adult rats approximately $27 \mathrm{mg} /$ 
$\mathrm{kg}$ ), and also has teratogenetic and embryotoxic effects in mice [10,11]. Moreover, chronic treatment of dinoseb has been reported to affect the testis in rats [16], and is known to cause alterations in the sperm motion without showing any specific testicular lesions during short term treatment [17, 18].

The objectives of this study were to assess the effects of dinoseb on sperm motility by investigating sperm motion parameters using the CASA system and to find out which parameters were sensitive and useful endpoints for testicular toxicants. In addition, intermittent administration (Experiment II) was conducted to examine the chronic effects of dinoseb, because the consecutive administration of dinoseb (Experiment I) deteriorated the general condition of rats beyond our expectation. Finally, we compared the effects of dinoseb on sperm motion in different-design studies, and evaluated the toxic effects of dinoseb on sperm quality from the results of these studies.

\section{Materials and Methods}

\section{Animals}

Male Sprague-Dawley rats (Crj:CD(SD)IGS) obtained from Charles River Japan, Inc. (Atsugi Breeding Center, Atsugi, Japan) were used. At 16 weeks old, the rats were randomly divided into three groups in experiment I, and into two groups in experiment II. The rats were individually housed in stainless-steel wire cages in a temperature $(24 \pm 1 \mathrm{C})$, humidity $(55 \pm 5 \%)$ and lighting (12-h light/dark cycle) controlled room. Food (CE-2, CLEA Japan, Inc., Tokyo, Japan) and tap water were given at all times throughout the study. All animals were sacrificed by ether anesthesia on the day of sperm motion analysis.

\section{Dosing solutions}

Dinoseb (4,6-dinitro-2-sec-butylphenol, Sigma Chemical Co., St. Louis, MO, USA) was dissolved in corn oil (Nacalai Tesque Inc., Kyoto, Japan). Concentrations of dinoseb were adjusted so that animals received $2 \mathrm{ml} / \mathrm{kg}$ body weight. Dosing solutions were prepared fresh, daily, immediately before dosing.

Study design

Experiment I: 60 male rats of 16 weeks of age were randomly distributed into 3 groups of 20 animals on Experimental Day 1 (the first day of administration). Rats were administered dinoseb by gavage for 3 consecutive days at doses of 5 or 7.5 $\mathrm{mg} / \mathrm{kg} / \mathrm{day}$. These were the doses of administration of dinoseb used in the study by Linder et al. [18]. Control animals received corn oil at $2 \mathrm{ml} / \mathrm{kg}$ body weight. After a withdrawal period of 12 days (Day 15), one half of the animals in each dose group were necropsied, and the other half were necropsied after a withdrawal period of 19 days (Day 22). The testes, epididymides, and ventral prostate from all animals were weighed.

Experiment II: 15 male rats were randomly distributed into 2 groups ( $\mathrm{n}=5$ in the control group; $\mathrm{n}=10$ in the dinoseb-treatment group) at 16 weeks old on Experimental Day 1 (the first day of administration). Animals in the dinoseb-treatment group were administered dinoseb at $7.5 \mathrm{mg} / \mathrm{kg}$ three times per week (on Monday, Wednesday, and Friday) for 3 weeks. Control animals received corn oil at $2-\mathrm{ml} / \mathrm{kg}$ body weight. After 9 doses, on Day 21 , all animals were necropsied, and the same organs as mentioned in Experiment I were weighed.

\section{Sperm motion analysis}

Sperm samples were obtained from the right distal cauda epididymis. Small punctures were made with a needle into the engorged tubule of the distal caudal epididymis. The flooding luminal contents of the cauda were collected and dispersed for approximately $5 \mathrm{~min}$ in pre-warmed (38 C) Medium 199 with Hank's salts (Gibco, Grand Island, NY, USA) containing $0.5 \%$ bovine serum albumin (Intergen, Purchase, NY, USA). Each sperm suspension was drawn by capillary action into a cannula of $100-\mu \mathrm{m}$ depth (MICROSLIDED \#HTR1099, VitroCom Inc., Mt. Lakes, NJ, USA), and at least 200 sperm from each sperm suspension were analyzed using the CASA system (HTM-IVOS version 10.6, Hamilton-Thorne Research, Beverly, MA, USA). The software settings of HTM-IVOS are listed in Table 1.

The nine parameters representing the sperm swimming characteristics (see Katz [18] for a review of sperm motion) in HTM-IVOS are percentage of motile sperm (MOT, the ratio of motile sperm to the total sperm examined, \%), percentage of progressive sperm (PRG, the ratio of sperm with VAP $>70 \mu \mathrm{m} / \mathrm{sec}$ and STR $>50 \%$ to the 
Table 1. HTM-IVOS parameter settings used in the sperm motion analysis (software version 10.6)

\begin{tabular}{lc}
\hline Parameter & Setting \\
\hline Frames acquired & 30 \\
Frame rate & $60 \mathrm{~Hz}$ \\
Minimum contrast & 87 \\
Minimum cell size & 2 pixels \\
Minimum static contrast & 25 \\
Straightness (STR), threshold & $50.0 \%$ \\
Low VAP cutoff & $25.0 \mu \mathrm{m} / \mathrm{sec}$ \\
Medium VAP cutoff & $70.0 \mu \mathrm{m} / \mathrm{sec}$ \\
Low VSL cutoff & $15.0 \mu \mathrm{m} / \mathrm{sec}$ \\
Head size, non-motile & 12 pixels \\
Head intensity, non-motile & 70 \\
Static head intensity & 0.25 to 2.95 \\
Static elongation & 0.30 to 2.57 \\
Slow cells motile & No \\
Points in tract & 16 to 30 \\
\hline
\end{tabular}

total sperm examined, \%), path velocity (VAP, the velocity of the smoothed average cell path, $\mu \mathrm{m} /$ $\mathrm{sec}$ ), straight-line velocity (VSL, velocity between the beginning and the end of the track, $\mu \mathrm{m} / \mathrm{sec}$ ), curvilinear velocity (VCL, velocity of total distance between each sperm tracks, $\mu \mathrm{m} / \mathrm{sec}$ ), lateral head displacement $(\mathrm{ALH}$, mean width of the head oscillation, $\mu \mathrm{m})$, beat cross frequency (BCF, frequency of cell track crossing the cell path, $\mathrm{Hz}$ ), straightness (STR, departure of the cell path from a straight line, VSL/VAP $\times 100 \%$ ), and linearity (LIN, departure of the cell track from a straight line, VSL/VCL $\times 100 \%$ ).

\section{Sperm counts}

After the collection for sperm motion analysis, the right caudal epididymis was stored at $-20 \mathrm{C}$ until measurement of sperm counts. The stored caudal epididymis was thawed to room temperature, and homogenized in $20 \mathrm{ml}$ distilled water for $2 \mathrm{~min}$. The sperm heads in the homogenized epididymis were counted using an Ident-Stain kit (Hamilton-Thorne Research, Beverly, MA, USA), and were counted by the CASA system [20].

\section{Statistical evaluation}

Data obtained in the present study were analyzed, where appropriate, to detect the significance of difference between the control and dinoseb treated groups at $p<0.05$.

Experiment I: quantitative continuous variables were analyzed first using Bartlett's test for equal variances. Based upon the outcome of Bartlett's test, either parametric or non-parametric analysis of variance (ANOVA) was performed. If the ANOVA was significant, the Dunnett or Scheffé type multiple comparison test was applied. If the ANOVA was not significant, the Kruskal-Wallis analysis of ranks was applied. In consequence, if a

Table 2. Summary of organ weights and sperm analysis in dinoseb treated rats on Day 15 (Experiment I)

\begin{tabular}{lccc}
\hline Treatment & Corn oil (control) & Dinoseb $5 \mathrm{mg} / \mathrm{kg}$ & Dinoseb $7.5 \mathrm{mg} / \mathrm{kg}$ \\
\hline Mortality & $0 / 10$ & $0 / 10$ & $1 / 10$ \\
\hline Body weight gain (g/14 days) & $24.7 \pm 23.4$ & $33.3 \pm 6.2$ & $16.8 \pm 12.1$ \\
\hline Relative organ weight (\% of body & weight at necropsy) & & \\
Testes & $0.622 \pm 0.055$ & $0.596 \pm 0.061$ & $0.603 \pm 0.061$ \\
Epididymides & $0.216 \pm 0.021$ & $0.216 \pm 0.014$ & $0.209 \pm 0.029$ \\
Ventral prostate & $0.111 \pm 0.032$ & $0.095 \pm 0.023$ & $0.119 \pm 0.018$ \\
\hline Computer-assisted sperm analysis & & & \\
MOT $(\%)$ & $87.6 \pm 15.0$ & $93.0 \pm 6.0$ & $83.8 \pm 13.2$ \\
PRG $(\%)$ & $73.3 \pm 15.5$ & $79.4 \pm 7.7$ & $70.2 \pm 12.2$ \\
VAP $(\mu \mathrm{m} / \mathrm{sec})$ & $138.2 \pm 15.3$ & $144.3 \pm 9.4$ & $137.8 \pm 4.0$ \\
VSL $(\mu \mathrm{m} / \mathrm{sec})$ & $92.8 \pm 12.2$ & $96.4 \pm 11.8$ & $92.5 \pm 4.5$ \\
VCL $(\mu \mathrm{m} / \mathrm{sec})$ & $301.0 \pm 32.0$ & $311.5 \pm 27.0$ & $299.1 \pm 17.0$ \\
ALH $(\mu \mathrm{m})$ & $18.3 \pm 1.6$ & $19.4 \pm 0.8$ & $18.4 \pm 0.8$ \\
BCF $(\mathrm{Hz})$ & $25.5 \pm 3.9$ & $23.0 \pm 2.1$ & $25.0 \pm 2.9$ \\
STR $(\%)$ & $67.2 \pm 3.4$ & $66.7 \pm 4.4$ & $67.3 \pm 2.8$ \\
LIN $(\%)$ & $30.9 \pm 2.0$ & $31.0 \pm 1.9$ & $31.1 \pm 1.3$ \\
\hline Epididymal sperm number/caudal weight (million / gram) & & \\
& $941.7 \pm 291.6$ & $944.2 \pm 146.8$ & $843.0 \pm 206.0$ \\
\hline
\end{tabular}

Data presented as the mean \pm SD. 
Table 3. Summary of organ weights and sperm analysis in dinoseb treated rats on Day 22 (Experiment I)

\begin{tabular}{lccc}
\hline Treatment & Corn oil (control) & Dinoseb $5 \mathrm{mg} / \mathrm{kg}$ & Dinoseb 7.5 mg/kg \\
\hline Mortality & $0 / 10$ & $0 / 10$ & $1 / 10$ \\
\hline Body weight gain (g/21 days) & $50.7 \pm 12.8$ & $50.5 \pm 15.3$ & $44.4 \pm 12.7$ \\
\hline \multicolumn{2}{c}{ Relative organ weight (\% of body weight at necropsy) } & & \\
Testes & $0.603 \pm 0.045$ & $0.567 \pm 0.047$ & $0.628 \pm 0.044$ \\
Epididymides & $0.212 \pm 0.023$ & $0.206 \pm 0.016$ & $0.212 \pm 0.017$ \\
Ventral prostate & $0.124 \pm 0.027$ & $0.119 \pm 0.027$ & $0.125 \pm 0.023$ \\
\hline Computer-assisted sperm analysis & & \\
MOT $(\%)$ & $86.7 \pm 15.8$ & $80.1 \pm 22.0$ & $55.8 \pm 33.3^{*}$ \\
PRG $(\%)$ & $69.6 \pm 15.6$ & $64.9 \pm 19.9$ & $42.1 \pm 26.1$ \\
VAP $(\mu \mathrm{m} / \mathrm{sec})$ & $130.9 \pm 15.1$ & $133.2 \pm 16.9$ & $103.7 \pm 34.6^{*}$ \\
VSL $(\mu \mathrm{m} / \mathrm{sec})$ & $83.6 \pm 12.9$ & $87.4 \pm 11.1$ & $67.0 \pm 25.1$ \\
VCL $(\mu \mathrm{m} / \mathrm{sec})$ & $288.2 \pm 38.9$ & $298.2 \pm 34.3$ & $234.9 \pm 60.7^{*}$ \\
ALH $(\mu \mathrm{m})$ & $18.1 \pm 2.0$ & $18.1 \pm 2.0$ & $12.9 \pm 7.5^{*}$ \\
BCF $(\mathrm{Hz})$ & $25.4 \pm 2.6$ & $26.0 \pm 3.0$ & $29.6 \pm 9.8$ \\
STR $(\%)$ & $64.0 \pm 4.0$ & $65.6 \pm 3.6$ & $63.4 \pm 4.7$ \\
LIN $(\%)$ & $29.2 \pm 2.0$ & $29.5 \pm 1.5$ & $28.1 \pm 5.8$ \\
\hline Epididymal sperm number/caudal weight (million / gram) & \\
& $904.0 \pm 330.6$ & $827.9 \pm 322.9$ & $588.3 \pm 153.6^{*}$
\end{tabular}

Data presented as the mean \pm SD.

* Significantly different from control, $P<0.05$.

significant difference was detected among groups, the Dunnett type multiple comparison test was applied.

Experiment II: Student's $t$-test or Aspin-Welch's $t$-test was performed, based upon the outcome of the F-test.

\section{Results}

\section{Experiment I}

Table 2 summarizes the Day 15 results of Experiment I, and Table 3 those of Day 22. After the first treatment of dinoseb at $7.5 \mathrm{mg} / \mathrm{kg}$, rats showed physical signs of toxicity including transient hypoactivity and tachypnea, but before the second treatment on Day 2 the rats appeared to be recovering. On Day 3, however, all rats in this group appeared weak, and on the following day (Day 4), 2 rats were found dead. Body weight gain in the $7.5 \mathrm{mg} / \mathrm{kg}$ dose group was reduced during the treatment period (data not shown), but the average body weights in the $7.5 \mathrm{mg} / \mathrm{kg}$ dose groups were similar to those of the corresponding control both on Day 15 and 22 (the day of necropsy). Physical signs of toxicity were not observed in rats treated with $5 \mathrm{mg} / \mathrm{kg}$. No rats in the $5 \mathrm{mg} / \mathrm{kg}$ dose group were found dead, and animals in this group had body weight gains similar to those of the control.

Absolute and relative organ weights (adjusted for terminal body weight) in both treatment groups on either experimental day did not differ from the control.

The sperm motion analysis by CASA revealed no effects of dinoseb on Day 15 (Table 2). On the other hand, changes in the sperm motion in the $7.5 \mathrm{mg} /$ $\mathrm{kg}$ dose group were detected by CASA on Day 22 (Table 3). The values of MOT, VAP, VCL and ALH in the $7.5 \mathrm{mg} / \mathrm{kg}$ dose group were significantly decreased compared to those of the control. The mean values of PRG and VSL were also decreased and that of BCF was increased in the $7.5 \mathrm{mg} / \mathrm{kg}$ dose group, but no statistical difference from the control existed.

The average sperm counts per caudal epididymal weight were not affected in any dinoseb treatment group on Day 15. However, the sperm count in the $7.5 \mathrm{mg} / \mathrm{kg}$ dose group was significantly decreased compared with that of the control on Day 22.

\section{Experiment II}

Table 4 showed the results of Experiment II. No animal died during the experimental period. The 
Table 4. Summary of organ weights and sperm analysis in dinoseb treated rats (Experiment II)

\begin{tabular}{lcc}
\hline Treatment & Corn oil (control) & Dinoseb $7.5 \mathrm{mg} / \mathrm{kg}$ \\
\hline Mortality & $0 / 5$ & $0 / 10$ \\
\hline Body weight gain (g/20 days) & $49.4 \pm 17.3$ & $33.3 \pm 21.2$ \\
\hline Relative organ weight (\% of body weight at necropsy) & \\
Testes & $0.624 \pm 0.038$ & $0.618 \pm 0.091$ \\
Epididymides & $0.226 \pm 0.025$ & $0.218 \pm 0.034$ \\
Ventral prostate & $0.126 \pm 0.042$ & $0.131 \pm 0.015$ \\
\hline Computer-assisted sperm analysis & & \\
MOT $(\%)$ & $92.4 \pm 6.6$ & $81.8 \pm 29.0$ \\
PRG $(\%)$ & $71.0 \pm 9.4$ & $61.8 \pm 22.6$ \\
VAP $(\mu \mathrm{m} / \mathrm{sec})$ & $139.1 \pm 11.1$ & $139.5 \pm 10.2$ \\
VSL $(\mu \mathrm{m} / \mathrm{sec})$ & $84.6 \pm 9.0$ & $85.1 \pm 8.0$ \\
VCL $(\mu \mathrm{m} / \mathrm{sec})$ & $300.7 \pm 27.1$ & $19.9 \pm 2.0$ \\
ALH $(\mu \mathrm{m})$ & $19.7 \pm 1.3$ & $23.5 \pm 3.8$ \\
BCF $(\mathrm{Hz})$ & $23.2 \pm 1.7$ & $61.4 \pm 3.5$ \\
STR $(\%)$ & $61.4 \pm 3.5$ & $28.7 . \pm 1.3$ \\
LIN $(\%)$ & $28.2 \pm 1.4$ &
\end{tabular}

Epididymal sperm number/caudal weight (million / gram)

$817.6 \pm 93.0$

$837.0 \pm 217.5$

Data presented as the mean \pm SD.
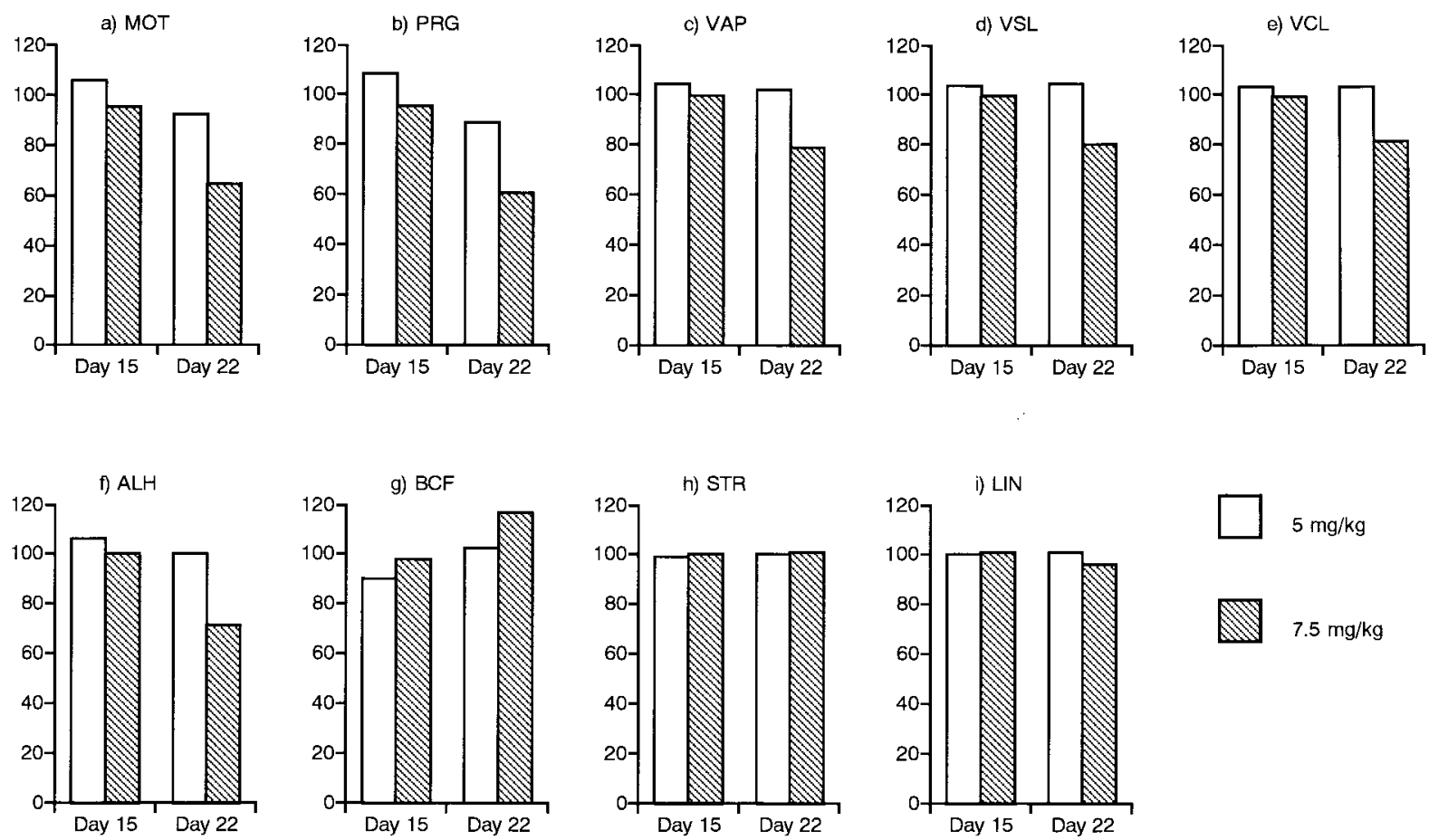

Fig. 1. Comparison of effects of dinoseb on parameters of CASA (Experiment I). Mean values of dinoseb treatment groups are shown relative to mean values of the control group expressed as $100 \%$. a) Percentage of motile sperm (MOT); b) percentage of progressively motile sperm (PRG); c) average path velocity (VAP); d) straight-line velocity (VSL); e) curvilinear velocity (VCL); f) amplitude of lateral head displacement (ALH); g) beat cross frequency (BCF); h) straightness (STR); and i) linearity (LIN).

mean body weight gain in the dinoseb treatment group was decreased when compared with the controls, but it was not statistically significant. Although rats in the dinoseb treatment group 
showed similar abnormal clinical conditions after treatment, as observed in Experiment I, no rats showed physical signs of toxicity at the time of the following administration.

Absolute and relative organ weights in the dinoseb treatment groups did not differ significantly from the controls (Table 4).

Under this condition of administration of dinoseb, there were no treatment related changes not only in the percentage of motile sperm but also among the other parameters including the caudal sperm count (Table 4).

\section{Discussion}

The CASA system can analyze not only the percentage of the motile sperm but also the sperm motion characteristics, such as the sperm swimming speed and sperm swimming pattern. The objective of this study was to identify which sperm motion parameters are sensitive and useful for evaluating the effects of chemicals on sperm motion using the CASA system, and in addition, to evaluate the toxicity of dinoseb on sperm quality by comparing the data with a different-design study.

Figure 1 shows the percentages of effects of dinoseb on each parameter obtained from the CASA system in Experiment I. Among the parameters for which data were obtained by CASA analysis, the most sensitive parameters related to the treatment with dinoseb were MOT, VAP, VCL and ALH. Slightly less sensitive parameters were thought to be PRG, VSL, and BCF. Although statistically significant effects may not have been observed in these three parameters because of their relatively larger values of standard deviation, the rates of alteration of these parameters were similar to those of MOT, VAP, VCL and ALH (see Fig. 1). Because the larger values of VAP, VSL, ALH and PRG represent more vigorous and progressive movement of sperm, the results of Experiment I showed that the motion of dinoseb treated sperm was slow and wobbling. On the other hand, the parameters of STR and LIN showed no effects related to treatment with dinoseb. Since these two parameters, STR and LIN, are calculated from the values of VAP, VSL or VCL, they might not represent treatment related alterations in sperm motility, when all of VAP, VSL and VCL synchronously changed. Depending on the altered sperm motion, one must consider the risks of these parameters showing "false negative" effects.

In humans, several studies have shown that the sperm motile characteristics, especially the swimming speed, were of the utmost importance for fertility [21-23]. Hinting et al. [24] reported the best discrimination between fertile and subfertile men was the proportion and concentration of sperm with rapid linear progressive velocity. In the present study, the values of VAP and VCL representing the sperm swimming speed were significantly decreased by the administrations of dinoseb. In addition to these parameters, the VSL and RPG were decreased considerably though without statistical significance. Although we did not examine the fertility of dinoseb treated male rats, we presume the dinoseb treated rats had little fertility in the light of their sperm motion.

In this study, only those rats administered 7.5 $\mathrm{mg} / \mathrm{kg}$ dinoseb for 3 consecutive days and sacrificed after a withdrawal period of 19 days showed dinoseb-related alteration in sperm motion and caudal sperm reservation. Neither in rats administered $5 \mathrm{mg} / \mathrm{kg}$ dinoseb with both withdrawal periods of 12 days or 19 days, nor in rats administered $7.5 \mathrm{mg} / \mathrm{kg}$ dinoseb with a withdrawal period of 12 days, were there remarkable effects of dinoseb on the sperm motion. In addition, the sperm counts in the caudal epididymis were decreased only in rats administered $7.5 \mathrm{mg} / \mathrm{kg}$ dinoseb after a withdrawal period of 19 days. These findings confirmed those of earlier investigations showing the percentage of motile sperm decreased in rats treated with dinoseb at $7.5 \mathrm{mg} / \mathrm{kg}$ for 5 days and examined after 13 days withdrawal period [18], and abnormal sperm observed not 10 days but 20 days treatment in rats fed $300 \mathrm{ppm}$ dinoseb [17]. Considering the transit time of the sperm through the epididymis and decrease in sperm number of the caudal epididymis, sperm with reduced motility due to dinoseb might have originated in the spermatogenesis process in the testis, when they were spermatids or spermatocytes (Experiment I).

Unexpectedly, no rats treated with dinoseb intermittently (Experiment II) showed obvious toxicity in the sperm evaluation. Under these administration conditions, rats were administered larger amounts of dinoseb than rats in Experiment I; therefore, the mean body weight gain of dinoseb 
treated rats in Experiment II (33.2 g) was reduced when compared with those of rats administered 7.5 $\mathrm{mg} / \mathrm{kg}$ dinoseb in Experiment I with a withdrawal of 19 days (49.4 g). Radio-labeled dinoseb orally given to rats was nearly completely excreted within 72 hours. However, after 24 hours of treatment, about $40 \%$ of dinoseb was yet to be excreted [25]. In addition, Giavini et al. [26] found that depending upon the various methods of administration to pregnant rats, the effects of dinoseb differed in the maternal toxicity, embryotoxicity or teratogenesity. From these findings, the toxicity of dinoseb on sperm may greatly depend on the absorption, distribution, metabolism, or excretion (ADME) of the compound. It is considered that the consecutive administrations of dinoseb (Experiment I) specifically affected the testis and the toxic effects were observed in the sperm motion.

In conclusion, the CASA system is useful for detecting toxicity through sperm motion, and moreover, the parameters of CASA representing sperm motion characteristics may become useful endpoints. Furthermore, unless the testis or the epididymis is examined histopathologically, the examination of the sperm motility by CASA may give some helpful information on toxicity. In addition, flexible study designs combined with short duration studies can provide complementary data on toxicity, even though the mechanism of toxicity and cellular target of each compound varies. Under the conditions of the present study, the most sensitive parameters of the CASA system were the percentage of motile sperm, the path velocity, the curvilinear velocity, and the amplitude of the lateral head displacement.

\section{Acknowledgements}

The authors wish to thank Dr. Kunio Kawashima, National Institute of Health Science, for useful suggestions.

\section{References}

1. Blazak WF, Ernst TL, Stewart BE. Potential indicators of reproductive toxicity: testicular sperm production and epididymal sperm number, transit time, and motility in Fischer 344 rats. Fundam Appl Toxicol 1985; 5: 1097-1103.

2. Zenick $\mathbf{H}, \mathbf{C l e g g}$ ED. Issues in risk assessment in male reproductive toxicology. J Am Coll Toxicol 1986; 5: 249-259.

3. Lamb IV JC, Ross MD, Chapin RE. Experimental methods for studying male reproductive function in standard toxicology studies. J Am Coll Toxicol 1986; 5: 225-234.

4. Morrissey RE, Schwetz BA, Lamb IV JC, Ross MD, Teague JL, Morris RW. Evaluation of rodent sperm, vaginal cytology, and reproductive organ weight data from National Toxicology Program 13-week studies. Fundam Appl Toxicol 1988; 11: 343-358.

5. Working PK. Male reproductive toxicology: comparison of the human to animal models. Environ Health Perspect 1988; 77: 37-44.

6. Klinfelter GR, Gray Jr. LE, Suarez JD. The method of sperm collection significantly influences sperm parameters following ethane dimethanesulphonate administration in the rat. Reprod Toxicol 1991; 5: 3944.

7. Chapin RE, Filler RS, Gulati D, Heindel JJ, Katz DF, Mebus CA, Obasaju F, Perreault SD, Russell SR, Schrader S, Slott V, Sokol RZ, Toth G.
Methods for assessing rat sperm motility. Reprod Toxicol 1992; 6: 267-273.

8. Slott VL, Suarez JD, Poss PM, Linder RE, Strader LF, Perreault SD. Optimization of the HamiltonThorn computerized sperm motility analysis system for use with rat spermatozoa in toxicological studies. Fundam Appl Toxicol 1993; 21: 298-307.

9. Amann RP. Use of animal models for detecting specific alterations in reproduction. Fundam Appl Toxicol 1982; 2: 13-26.

10. Ilivicky J, Casida JE. Uncoupling action of 2,4dinitrophenols, 2-trifluoromethylbenzimidazoles and certain other pesticide chemicals upon mitochondria from different sources and its relation to toxicity. Biochem Pharmacol 1969; 18: 1389-1401.

11. Gibson JE. Teratology studies in mice with 2-secbutyl-4,6-dinitrophenol (dinoseb). Fd Cosmet Toxicol 1973; 11: 31-43.

12. Gains TB, Linder RE. Acute toxicity of pesticides in adult and weanling rats. Fundam Appl Toxicol 1986; 7: 299-308.

13. Giavini E, Broccia ML, Prati M, Cova D, Rossini L. Teratogenicity of dinoseb: role of the diet. Bill Environ Contam Toxicol 1989; 43: 215-219.

14. Daston GP, Rogers JM, Versteeg DJ, Sabourin TD, Baines D, Marsh SS. Interspecies comparisons of A/D ratios: A/D ratios are not constant across species. Fundam Appl Toxicol 1991; 17: 696-722. 
15. Branch S, Rogers JM, Brownie CF, Chernoff $\mathbf{N}$. Surpernumerary lumber rib: manifestation of basic alteration in embryonic development of ribs. J Appl Toxicol 1996; 16: 115-119.

16. Linder RL, Scotti TM, Svendsgaard DJ, McElroy WK, Curley A. Testicular effects of dinoseb in rats. Arch Environm Contam Toxicol 1982; 11: 475-485.

17. Linder RL, Strader LF, McElroy WK. Measurement of epididymal sperm motility as a test variable in the rats. Bull Environ Contam Toxicol 1986; 36: 317-324.

18. Linder RL, Strader LF, Slott, VL, Suarez JD. Endpoints of spermatotoxicity in the rat after short duration exposures to fourteen reproductive toxicants. Reprod Toxicol 1992; 6: 491-505.

19. Katz DF. Characteristics of sperm motility. Ann NY Acad Sci 1991; 637: 409-423.

20. Strader LF, Linder RE, Perreault SD. Comparison of rat epididymal sperm counts by IVOS HTMIDENT and hemacytometer. Reprod Toxicol 1996; 10: 529-533.

21. Aitken RJ, Best FSM, Richardson DW, Djahanbakhch O, Mortimer D, Templeton AA, Lees MM. An analysis of sperm function in cases of unexplained infertility: conventional criteria, movement characteristics, and fertilizing capacity. Fertil Steril 1982; 38: 212-221.

22. Holt WV, Moore HDM, Hillier SG. Computerassisted measurement of sperm swimming speed in human semen: correlation of results with in vitro fertilization assays. Fertil Steril 1985; 44: 112-119.

23. Mathur S, Carlton M, Ziegler J, Rust PF, Williamson HO. A computerized sperm motion analysis. Fertil Steril 1986; 46: 484-488.

24. Hinting A, Comhaire F, Schoonjans F. Capacity of objectively assessed sperm motility characteristics in differentiating between semen of fertile and subfertile men. Fertil Steril 1988; 50: 635-639.

25. Bandal SK, Casida JE. Metabolism and photoalteration of 2-sec-butyl-4,6-dinitrophenol (DNBP herbicide) and its isopropyl carbonate derivative (dinobuton acaricide). J Agr Food Chem 1972; 20: 1235-1245.

26. Giavini E, Broccia ML, Prati M, Vismara C. Effect of methods of administration on the teratogenicity of dinoseb in the rat. Arch Environ Contam Toxicol 1986; 15: 377-384. 